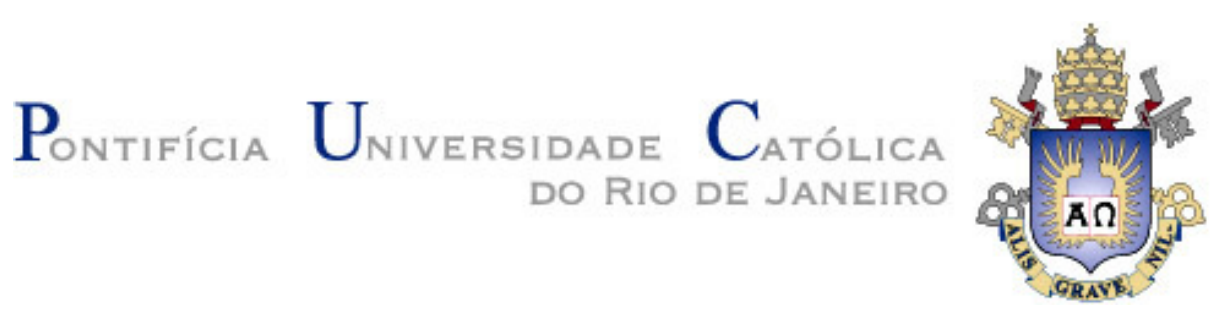

Lucas Boabaid Ibrahim

\title{
Análise numérica e experimental da mecânica de formação de aneurismas da aorta abdominal
}

Tese apresentada ao programa de Pós-Graduação em Engenharia Civil como requisito parcial para obtenção do título de Doutor em Engenharia Civil.

Orientadora: Djenane Cordeiro Pamplona

Rio de Janeiro, agosto de 2010 


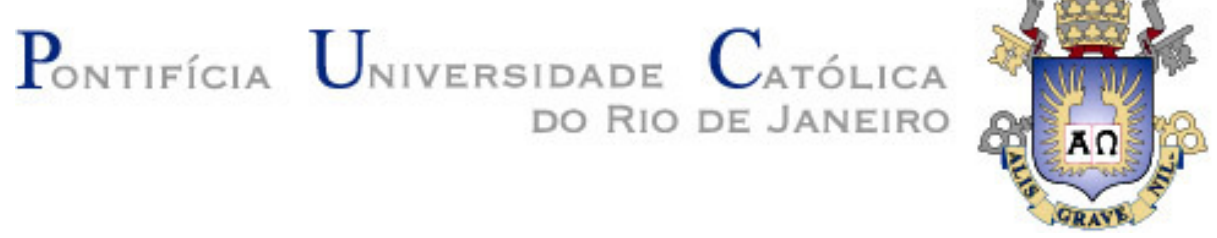

Lucas Boabaid Ibrahim

Análise numérica e experimental da mecânica de formação de aneurismas da aorta abdominal

Tese apresentada como requisito parcial para obtenção do título de Doutor pelo Programa de Pós-Graduação em Engenharia Civil da PUC-Rio. Aprovada pela Comissão Examinadora abaixo assinada.

Prof ${ }^{a}$. Djenane Cordeiro Pamplona Orientadora Departamento de Engenharia Civil - PUC-Rio

Prof. Ney Augusto Dumont Departamento de Engenharia Civil - PUC-Rio

Prof. Paulo Batista Gonçalves Departamento de Engenharia Civil - PÜC-Rio

Prof. Agenor de Toledo Fleury Centro Universitário da FEI

Prof. Carlos Eduardo Virgini Magalhães UERJ

Prof. Claudio Ribeiro Carvalho UFF

Prof. Prof. José Eugenio Leal Coordenador Setorial do Centro Técnico Científico - PUC - Rio

Rio de janeiro, 03 de agosto de 2010 
Todos os direitos reservados. É proibida a reprodução total ou parcial do trabalho sem autorização da universidade, do autor e do orientador.

\section{Lucas Boabaid Ibrahim}

Graduou-se Engenheiro Civil em Dezembro de 2003, pela Faculdade de Engenharia Industrial (FEI)

Possui Mestrado em Engenharia Civil pelo Departamento de Engenharia Civil - PUC-Rio

Ficha Catalográfica

Ibrahim, Lucas Boabaid
Análise numérica e experimental da
mecânica de formação de aneurismas da aorta
abdominal / Lucas Boabaid lbrahim ; orientadora:
Djenane Cordeiro Pamplona. -2010.
272 f. : il. (color.) ; $30 \mathrm{~cm}$
Tese
(Doutorado)-Pontifícia
Departamento de Engenharia Civil, 2010.
Inclui bibliografia
1. Engenharia civil - Teses. 2.

Aneurisma. 2. Elementos finitos. 3. Instabilidade.

4. Deformações finitas. I. Pamplona, Djenane Cordeiro. II. Pontifícia Universidade Católica do Rio de Janeiro. Departamento de Engenharia Civil. III. Título.

CDD: 624 
Aos meus pais, amigos e a todos que contribuíram na realização deste trabalho. 


\section{Agradecimentos}

À PUC-Rio e aos professores do Departamento de Engenharia Civil.

A minha orientadora, pela convivência, disponibilidade, incentivo, paciência e pelos conhecimentos transmitidos durante estes últimos anos.

À banca examinadora.

Aos meus colegas durante estes quatro anos.

Aos funcionários do departamento de Engenharia Civil.

Ao CNPq pela bolsa e à FAPERJ e CAPES pelo suporte à pesquisa. 


\section{Resumo}

Ibhahim, Lucas Boabaid; Pamplona, Djenane Cordeiro. Análise numérica e experimental da mecânica de formação de aneurismas da aorta abdominal. Rio de Janeiro, 2010. 272p. Dissertação de Doutorado Departamento de Engenharia Civil, Pontifícia Universidade Católica do Rio de Janeiro.

Esta tese tem por objetivo investigar numérica e experimentalmente a mecânica da formação dos aneurismas na aorta abdominal. A parte experimental foi realizada no Laboratório de Membranas e Biomembranas utilizando-se tubos de silicone com a geometria aproximada da aorta sob pressão hidrostática. Foi investigada a pressão necessária à formação dos aneurismas e o comportamento do material ensaiado. A parte numérica foi realizada por meio do método dos elementos finitos através do programa ABAQUS (6.8.1). Com a análise numérica foi validada a análise experimental. Foram estudados casos de imperfeição geométrica e física do material, usando equações constitutivas propostas para o material da aorta.

\section{Palavras-chave}

Aneurisma; elementos finitos; instabilidade; deformações finitas 


\section{Abstract}

Ibhahim, Lucas Boabaid; Pamplona, Djenane Cordeiro (Advisor). Numerical and experimental analysis of mechanics of formation of abdominal aortic aneurysms. Rio de Janeiro, 2010. 272p. DSc. Disseraation - Departamento de Engenharia Civil, Pontifícia Universidade Católica do Rio de Janeiro.

The aim of this work is to investigate numerically and experimentally the mechanics of aortic aneurisms. The experimental part was performed at the Laboratory of Membranes and Biomembranes using silicone tubes with the geometry of the aorta under hydrostatic pressure. We investigate the behavior of the material tested and the critical pressure, this is the pressure necessary for the formation of aneurysms. The numerical analysis is done using the finite element code ABAQUS (6.8.1), and is validated by the experimental analysis. Some studies of geometrical and physical imperfections are performed, as well as the ones with constitutive equations for the material of the aorta.

\section{Keywords}

Aneurysm; finite elements; instability; finite deformation 


\section{Sumário}

1 Introdução 32

1.1. Objetivo da dissertação 33

1.2. Organização do texto 34

2 Revisão bibliográfica $\quad 36$

2.1. Definição de aneurismas 36

2.2. Tipos de aneurismas $\quad 37$

2.3. Prevalência 39

2.4. Aorta 40

2.5. Divisão da artéria aorta 42

2.6. Camadas da parede arterial 44

2.7. Etiopatogenia 45

2.8. História 46

2.9. Risco de ruptura e morte $\quad 47$

2.10. Fatores de risco de ruptura 47

2.11. Diagnósticos clínicos e exames subsidiários 49

2.12. Estudos de modelagens encontradas 50

2.13. Estudo microscópico do tecido arterial 57

3 Analise experimental $\quad 59$

3.1. Aparato utilizado na análise experimental 61

3.2. Descrição do procedimento realizado na análise experimental 62

3.3. Escolha do material 63

3.4. Confecção do tubo de silicone 64

3.5. Obtenção das propriedades do silicone 65

3.5.1. Corpo de prova 68

3.5.2. Pré-condicionamento 68

3.6. Resultados dos ensaios com tubos de silicone 69

$\begin{array}{ll}\text { 3.7. Estudo da pressão } & 69\end{array}$ 
3.8. Estudo da variação volumétrica 70

3.9. Ensaios experimentais 70

3.9.1. Ensaio 1

3.9.2. Ensaio 2

3.9.3. Ensaio $3 \quad 75$

3.9.4. Ensaio $4 \quad 78$

3.9.5. Ensaio $5 \quad 80$

3.9.6. Ensaio 6

3.10. Padronização das pressões críticas 85

3.11. Padronização da análise do volume 86

3.12. Repetibilidade do ensaio 87

3.13. Causas da variação da pressão crítica 88

4 Análise numérica $\quad 90$

4.1. Descrição da análise numérica 90

4.2. Formulação dos funcionais de energia 91

4.3. Escolha do funcional de energia 93

4.4. Definição da geometria 96

4.4.1. Elemento de casca 96

4.4.2. Elemento sólido 97

4.5. Análise de convergência 98

4.5.1. Análise de convergência de elemento de casca 98

4.5.2. Análise de convergência de elemento sólido 101

4.6. Análise da pressão crítica 103

4.6.1. Análise da pressão crítica com elementos de casca e funcional de energia Ogden 104

4.6.1.1. Sem alongamento 104

4.6.1.2. Alongamento de $10 \% \quad 105$

4.6.1.3. Alongamento de 20\% 105

4.6.1.4. Comparação dos elementos de casca 106

4.6.2. Análise da pressão crítica com elementos de casca e funcional de energia Neo Hooke 107

$\begin{array}{ll}\text { 4.6.2.1. Sem alongamento } & 107\end{array}$ 
4.6.2.2. Alongamento de $10 \%$

4.6.2.3. Alongamento de $20 \%$

4.6.2.4. Comparação dos elementos de casca

4.6.3. Análise da pressão crítica com elementos sólidos e funcional de energia Ogden

4.6.3.1. Sem alongamento

4.6.3.2. Alongamento de $10 \%$

4.6.3.3. Alongamento de $20 \%$

4.6.3.4. Comparação dos elementos sólidos

4.6.4. Análise da pressão crítica com elementos sólidos e funcional de energia Neo Hooke

4.6.4.1. Sem alongamento

4.6.4.2. Alongamento de $10 \%$

4.6.4.3. Alongamento de $20 \%$

4.6.4.4. Comparação dos elementos sólidos

4.6.5. Comparação dos elementos de casca e sólidos

4.7. Estudo das imperfeições impostas

4.7.1. Análise da pressão crítica para imperfeição anelar inferior

123

4.7.2. Análise da pressão crítica para imperfeição anelar superior

126

4.7.3. Análise da pressão crítica para imperfeição local

130

4.7.3.1. Caso 1

130

4.7.3.1.1. Caso 1 - modelo perfeito

4.7.3.1.2. Caso 1 - espessura de $3,0 \mathrm{~mm}$

132

4.7.3.1.3. Caso 1 - espessura de $2,5 \mathrm{~mm}$

4.7.3.1.4. Caso 1 - espessura de $2,0 \mathrm{~mm}$

4.7.3.1.5. Caso 1 - espessura de $1,5 \mathrm{~mm}$

4.7.3.1.6. Caso 1 - espessura de $1,0 \mathrm{~mm}$

4.7.3.1.7. Estudo comparativo do caso 1

4.7.3.2.1. Caso 2 - espessura $3,0 \mathrm{~mm}$

4.7.3.2.2. Caso 2 - espessura $2,5 \mathrm{~mm}$ 
4.7.3.2.5. Caso 2 - espessura 1,0 mm 142

4.7.3.2.6. Estudo comparativo do caso 2

4.7.3.3. Caso $3 \quad 145$

4.7.3.3.1. Caso 3 - espessura de 3,0 mm 146

4.7.3.3.2. Caso 3 - espessura de 2,5 mm 147

4.7.3.3.3. Caso 3 - espessura de 2,0 mm 147

4.7.3.3.4. Caso 3 - espessura de 1,5 mm 148

4.7.3.3.5. Caso 3 - espessura de 1,0 mm 151

4.7.3.3.6. Estudo comparativo do caso 3

4.7.3.4. Caso 4

4.7.3.4.1. Caso 4 - espessura de 3,0 mm 153

4.7.3.4.2. Caso 4 - espessura de 2,5 mm 154

4.7.3.4.3. Caso 4 - espessura de 2,0 mm 154

4.7.3.4.4. Caso 4 - espessura de 1,5 mm 155

4.7.3.4.5. Caso 4 - espessura de 1,0 mm 156

4.7.3.4.6. Estudo comparativo do caso 4

4.7.3.5. Estudo comparativo da análise da pressão crítica para imperfeição local 159

4.7.4. Análise da pressão crítica para imperfeições geradas por $\begin{array}{ll}\text { excentricidade } & 161\end{array}$

4.7.4.1. Ogden - excentricidade de 0,5 161

4.7.4.2. Avaliação gráfica 163

4.7.4.3. Neo Hooke - excentricidade de 0,5 165

$\begin{array}{ll}\text { 4.7.4.4. Avaliação gráfica } & 167\end{array}$

4.7.4.5. Ogden - excentricidade de 1,0 169

4.7.4.6. Avaliação gráfica 171

4.7.4.7. Neo Hooke - excentricidade de 1,0 173

4.7.4.8. Avaliação gráfica 176

4.7.4.9. Ogden - excentricidade de 1,5 178

4.7.4.10. Avaliação gráfica 180

4.7.4.11. Neo Hooke - excentricidade de 1,5 182

4.7.4.12. Avaliação gráfica 184

4.7.4.13. Ogden - excentricidade de 2,0 186 
4.7.4.15. Neo Hooke - excentricidade de 2,0 190

4.7.4.16. Avaliação gráfica 192

4.7.5. Análise da pressão crítica para imperfeição gerada por excentricidade e diminuição da constante elástica

4.7.5.1. Análise da sensibilidade da pressão crítica com a perda das propriedades elásticas para excentricidade de 0,5

4.7.5.2. Avaliação gráfica

4.7.5.3. Análise da sensibilidade da pressão crítica com a perda das propriedades elásticas para excentricidade de 1,0

4.7.5.5. Análise da sensibilidade da pressão crítica com a perda das propriedades elásticas para excentricidade de 1,5

4.7.5.6. Avaliação gráfica

4.7.5.7. Análise da sensibilidade da pressão crítica com a perda das propriedades elásticas para excentricidade de 2,0 212

5. Análise numérica realizada com as características da parede arterial220

5.1. Primeiro estudo das propriedades da aorta 220

5.1.1. Escolha do funcional de energia 221

5.1.2. Análise de convergência 223

5.1.3. Análise da pressão crítica com elementos de casca e funcional de energia Ogden 1

5.1.3.1. Sem alongamento

5.1.3.2. Alongamento de $10 \%$

5.1.3.3. Alongamento de $20 \%$ 226

5.1.3.4. Comparação da pressão crítica para Ogden 1

5.1.4. Análise da pressão crítica com elementos de casca e funcional de energia Yeoh

5.1.4.1. Sem alongamento 228

5.1.4.2. Alongamento de $10 \%$ 229

5.1.4.3. Alongamento de $20 \%$ 
5.1.4.4. Comparação da pressão crítica para Yeoh

5.2. Segundo estudo das propriedades da aorta 231

5.2.1. Equação constitutiva de Delfino 231

5.2.2. Equação constitutiva de Sacks 233

5.2.2.1. Equação constitutiva de Sacks aplicada a espessura da media

5.2.2.2. Equação constitutiva de Sacks aplicada a espessura da media e geometria de D.P. Sokolis

5.3. Estudo da degeneração local do tecido arterial para a formação do aneurisma

5.3.1. Primeiro estudo das imperfeições locais dos aneurismas

5.3.2. Segundo estudo das imperfeições locais dos aneurismas

6. Resultados finais

6.1. Tubos de silicone

6.1.1. Comparação entre os resultados da pressão crítica

6.1.2. Comparação entre os resultados da tensão

6.2. Comparação da pressão crítica dos estudos de imperfeição

6.2.1. Análise da pressão crítica para imperfeições locais simétricas

6.2.2. Análise da pressão crítica para imperfeições locais assimétricas 251

6.2.3. Análise dos elementos sólidos com excentricidade

6.2.4. Análise dos elementos sólidos com excentricidade e variação da constante elástica

6.3. Comparação entre os resultados da pressão crítica obtidas numérica e experimentalmente

6.4. Avaliação da pressão para o gráfico tensão deformação proposto por Sacks

6.5. Estudo das equações constitutivas de artéria

6.7. Trabalhos futuros

7. Bibliografia 


\section{Lista de Figuras}

Figura 1.1 - Exemplo de aneurismas - John A. Elefteriades (2006) 32

Figura 2.1 - Exemplo de dilatação permanente e localizada -

http://www.gforum.tv/board/1092/285283/um-importante-avanco-no-

entendimento-dos-aneurismas-cerebrais.html

Figura 2.2 - Representação da ruptura do aneurisma - John A.

Elefteriades (2006)

Figura 2.3 - Representação da dissecção dos aneurismas - John A.

Elefteriades (2006)

Figura 2.4 - Corte transversal do aneurisma de dissecção - John A.

Elefteriades (2006)

Figura 2.5 - Local da maior incidência dos aneurismas -

http://copy.pnn.pt/noticias_imagens/aneurisma_aorta.jpg

Figura 2.6 - Exemplo de aneurisma na aorta abdominal -

http://www.hospiten.es/hospiten/HOSPITEN/published/DEFAULT/CMI/DT

E/aaa/aneurisma0007.jpg 40

Figura 2.7 - Espessura da parede arterial após a formação do aneurisma -

John A. Elefteriades (2006)

Figura 2.8 - Variação da espessura da parede arterial no local de ruptura do aneurisma - Madhavan L. Raghavan e outros (2006)

Figura 2.9 - Representação da aorta e dos principais órgãos do corpo humano - http://manualmerck.net/images/thumbnail/p_140.gif

Figura 2.10 - Representação da aorta segmentada -

http://manualmerck.net/images/thumbnail/p_141.gif

Figura 2.11 - Camadas constituintes da aorta - Gerhard A. Holzapfel (2000)

Figura 2.12 - Exemplo de próteses usadas na reparação de aneurismas http://manualmerck.net/images/thumbnail/p_142-1.gif

Figura 2.13 - Imagem gerada por angiorressonância - 
Figura 2.14 - Gráfico de energia da camada luminal

Figura 2.15 - Microscopia realizada no tecido arterial - D. P. Sokolis (2006)

Figura 3.1 - Variação da espessura da parede arterial proposta por D. P.

Sokolis (2007)

Figura 3.2 - Variação do diâmetro interno e externo da parede arterial proposta por D. P. Sokolis (2007)

Figura 3.3 - Equipamentos utilizados na análise experimental

Figura 3.4 - Corpos de prova para determinação da concentração de catalisador

Figura 3.5 - Processo para retirada de bolhas da mistura

Figura 3.6 - Detalhes do molde de gesso utilizado na confecção do tubo de silicone

Figura 3.7 - Detalhe da garra utilizada no ensaio de tração do corpo de prova

Figura 3.8 - Detalhe do ensaio de tração

Figura 3.9 - Representação dos corpos de prova e da artéria

Figura 3.10 - Seqüência de fotos ao longo do ensaio (pressões em $\mathrm{mmHg}$ )

Figura 3.11 - Gráfico de caracterização do ensaio 1

Figura 3.12 - Variação da pressão do ensaio 1

Figura 3.13 - Variação do volume do ensaio 1

Figura 3.14 - Gráfico de caracterização do ensaio 2

Figura 3.15 - Variação da pressão do ensaio 2

Figura 3.16 - Variação do volume do ensaio 2

Figura 3.17 - Seqüência de fotos ao longo do ensaio (pressões em $\mathrm{mmHg}$ )

Figura 3.18 - Gráfico de caracterização do ensaio 3

Figura 3.19 - Variação da pressão do ensaio 3

Figura 3.20 - Variação do volume do ensaio 3

Figura 3.21 - Gráfico de caracterização do ensaio 4

Figura 3.22 - Variação da pressão do ensaio 4 79

Figura 3.23 - Variação do volume do ensaio 4 
Figura 3.24 - Seqüência de fotos ao longo do ensaio (pressões em $\mathrm{mmHg}$ )

Figura 3.25 - Gráfico de caracterização do ensaio 5

Figura 3.26 - Variação da pressão do ensaio 5

Figura 3.27 - Variação do volume do ensaio 5

Figura 3.28 - Gráfico de caracterização do ensaio $6 \quad 84$

Figura 3.29 - Variação da pressão do ensaio $6 \quad 84$

Figura 3.30 - Variação do volume do ensaio $6 \quad 85$

Figura 3.31 - Análise da variação da pressão 86

Figura 3.32 - Análise da variação do volume 87

Figura 3.33 - Gráfico de caracterização do ensaio 7

Figura 3.34 - Imperfeições $\quad 89$

Figura 4.1 - Caracterização numérica do material estudado 93

Figura 4.2 - Aproximação dos funcionais de energia 94

Figura 4.3 - Aproximação dos funcionais de energia estáveis $\quad 95$

Figura 4.4 - Representação esquemática da variação da espessura ao longo do comprimento para o elemento de casca 97

Figura 4.5 - Representação esquemática da variação da espessura ao longo do comprimento para o elemento sólido 98

Figura 4.6 - Gráfico demonstrativo da análise de convergência do elemento de casca para o funcional Ogden 1

Figura 4.7 - Malhas testadas para o elemento de casca 100

Figura 4.8 - Gráfico demonstrativo da análise de convergência do elemento de casca para o funcional Neo Hooke 100

Figura 4.9 - Gráfico demonstrativo da análise de convergência dos elementos sólidos para o funcional Ogden 1

Figura 4.10 - Malhas testadas para o elemento sólido 102

Figura 4.11 - Gráfico demonstrativo da análise de convergência dos elementos sólidos para o funcional Neo Hooke 102

Figura 4.12 - Malha adotada para a análise com elementos sólidos 103 Figura 4.13 - Configuração indeformada e deformada para o tubo de silicone sem alongamento 
Figura 4.14 - Configuração indeformação e deformada para o tubo de silicone com alongamento de $10 \%$

Figura 4.15 - Configuração indeformação e deformada para o tubo de silicone com alongamento de $20 \%$

Figura 4.16 - Variação da pressão em função do alongamento (\% do comprimento inicial)

Figura 4.17 - Variação da tensão máxima trativa principal para o elemento de casca

Figura 4.18 - Configuração indeformada e deformada para o tubo de silicone sem alongamento

Figura 4.19 - Configuração indeformada e deformada para o tubo de silicone com alongamento de $10 \%$

Figura 4.20 - Configuração indeformada e deformada para o tubo de silicone com alongamento de $20 \%$

Figura 4.21 - Variação da pressão em função do alongamento (\% do comprimento inicial)

Figura 4.22 - Variação da tensão máxima trativa principal para o elemento de casca

Figura 4.23 - Configuração indeformada e deformada para o tubo de silicone sem alongamento

Figura 4.24 - Configuração indeformada e deformada para o tubo de silicone com alongamento de $10 \%$

Figura 4.25 - Configuração indeformada e deformada para o tubo de silicone com alongamento de $20 \%$

Figura 4.26 - Variação da pressão em função do alongamento (\% do comprimento inicial)

Figura 4.27 - Variação da tensão máxima trativa principal para o elemento sólido

Figura 4.28 - Configuração indeformada e deformada para o tubo de silicone sem alongamento

Figura 4.29 - Configuração indeformada e deformada para o tubo de silicone com alongamento de $10 \%$

Figura 4.30 - Configuração indeformada e deformada para o tubo de 
silicone com alongamento de $20 \%$

Figura 4.31 - Variação da pressão em função do alongamento (\% do comprimento inicial)

Figura 4.32 - Variação da tensão máxima trativa principal para o elemento sólido

Figura 4.33 - Comparação da variação da pressão em função do alongamento (\% do comprimento inicial) para elementos de casca

Figura 4.34 - Comparação da variação da pressão em função do alongamento (\% do comprimento inicial) para elementos sólidos

Figura 4.35 - Comparação da variação da tensão máxima trativa principal em função do alongamento (\% do comprimento inicial) para os elementos de casca

Figura 4.36 - Comparação da variação da tensão máxima trativa principal em função do alongamento (\% do comprimento inicial) para os elementos sólidos

Figura 4.37 - Esquema da imperfeição em formato de anel

Figura 4.38 - (a), (b) e (c) Esquema da imperfeição em formato de semianel e (d) formato da área da seção transversal no corte AA

Figura 4.39 - Seção transversal da casca com círculos não concêntricos e excentricidade e

Figura 4.40 - Pressão crítica em função da diminuição da espessura da região anelar inferior e valor da pressão crítica no modelo perfeito

Figura 4.41 - (a) posição da imperfeição e (b), (c), (d), (e) e (f) configurações deformadas para 3,5 mm (modelo perfeito), 3,0 mm, 2,5 $\mathrm{mm}, 2,0 \mathrm{~mm}$ e $1,5 \mathrm{~mm}$

Figura 4.42 - Variação da tensão máxima trativa principal em função da diminuição da espessura da região anelar e valor da tensão máxima trativa principal no modelo perfeito

Figura 4.43 - Pressão crítica em função da diminuição da espessura da região anelar superior e valor da pressão crítica no modelo perfeito 127 Figura 4.44 - (a) posição da imperfeição e (b), (c), (d), (e), (f), (g) e (h) configurações deformadas para 4,3 mm (modelo perfeito), 4,0 mm, 3,5 $\mathrm{mm}, 3,0 \mathrm{~mm}, 2,5 \mathrm{~mm}, 2,0 \mathrm{~mm}$ e $1,5 \mathrm{~mm}$ 
Figura 4.45 - Variação da tensão máxima trativa principal em função da diminuição da espessura da região anelar e valor da tensão máxima trativa principal no modelo perfeito

Figura 4.46 - Posição do primeiro caso das imperfeições localizadas 131 Figura 4.47 - Configuração indeformada e deformada sem imperfeição131 Figura 4.48 - Configurações deformadas para imperfeição de 3,0 mm 132 Figura 4.49 - Configurações deformadas para imperfeição de 2,5 mm 133 Figura 4.50 - Configurações deformadas para imperfeição de 2,0 mm 133 Figura 4.51 - Configurações deformadas para imperfeição de 1,5 mm 134 Figura 4.52 - Configurações deformadas para imperfeição de 1,0 mm 135 Figura 4.53 - Configurações deformadas para imperfeição de $3,5 \mathrm{~mm}, 3,0$ $\mathrm{mm}, 2,5 \mathrm{~mm}, 2,0 \mathrm{~mm}, 1,5 \mathrm{~mm}$ e 1,0 $\mathrm{mm}$ para o caso 1 de imperfeições locais

Figura 4.54 - Variação da pressão crítica para o caso 1 e valor da pressão crítica no modelo perfeito

Figura 4.55 - Variação da tensão máxima trativa principal para o caso $1 \mathrm{e}$ valor da tensão máxima trativa principal no modelo perfeito 138

Figura 4.56 - Posição do segundo caso das imperfeições localizadas 139 Figura 4.57 - Configurações deformadas para imperfeição de 3,0 mm 139 Figura 4.58 - Configurações deformadas para imperfeição de 2,5 mm 140 Figura 4.59 - Configurações deformadas para imperfeição de 2,0 mm 141 Figura 4.60 - Configurações deformadas para imperfeição de $1,5 \mathrm{~mm} 142$ Figura 4.61 - Configurações deformadas para imperfeição de 1,0 mm 142 Figura 4.62 - Configurações deformadas para imperfeição de $3,0 \mathrm{~mm}, 2,5$ $\mathrm{mm}, 2,0 \mathrm{~mm}, 1,5 \mathrm{~mm}$ e 1,0 mm para o caso 2 de imperfeições locais 143 Figura 4.63 - Variação da pressão crítica para o caso 2 e valor da pressão crítica no modelo perfeito

Figura 4.64 - Variação da tensão máxima trativa principal para o caso $2 \mathrm{e}$ valor da tensão máxima trativa principal no modelo perfeito

Figura 4.65 - Posição do segundo caso das imperfeições localizadas 146 Figura 4.66 - Configurações deformadas para imperfeição de 3,0 mm 146 Figura 4.67 - Configurações deformadas para imperfeição de 2,5 mm 147 Figura 4.68 - Configurações deformadas para imperfeição de 2,0 mm 148 
Figura 4.69 - Configurações deformadas para imperfeição de 1,5 mm 148 Figura 4.70 - Configurações deformadas para imperfeição de 1,0 mm 149 Figura 4.71 - Configurações deformadas para imperfeição de 3,0 mm, 2,5 $\mathrm{mm}, 2,0 \mathrm{~mm}, 1,5 \mathrm{~mm}$ e 1,0 $\mathrm{mm}$ para o caso 3 de imperfeições locais 150 Figura 4.72 - Variação da pressão crítica para o caso 3 e valor da pressão crítica no modelo perfeito

Figura 4.73 - Variação da tensão máxima trativa principal para o caso 3 e valor da tensão máxima trativa principal no modelo perfeito 152

Figura 4.74 - Posição do segundo caso das imperfeições localizadas 153 Figura 4.75 - Configurações deformadas para imperfeição de 3,0 mm 153 Figura 4.76 - Configurações deformadas para imperfeição de 2,5 mm 154 Figura 4.77 - Configurações deformadas para imperfeição de 2,0 mm 155 Figura 4.78 - Configurações deformadas para imperfeição de 1,5 mm 155 Figura 4.79 - Configurações deformadas para imperfeição de 1,0 mm 156 Figura 4.80 - Configurações deformadas para imperfeição de 3,0 mm, 2,5 $\mathrm{mm}, 2,0 \mathrm{~mm}, 1,5 \mathrm{~mm}$ e 1,0 mm para o caso 4 de imperfeições locais 157 Figura 4.81 - Variação da pressão crítica para o caso 4 e valor da pressão crítica no modelo perfeito

Figura 4.82 - Variação da tensão máxima trativa principal para o caso 4

Figura 4.83 - Posição das imperfeições para os casos estudados (a) caso 1, (b) caso 2, (c) caso 3, (d) caso 4; figuras fora de escala

Figura 4.84 - Variação da pressão crítica em função de imperfeições locais

Figura 4.85 - Configuração indeformada e deformada para Ogden - Sem alongamento - excentricidade de 0,5

Figura 4.86 - Configuração indeformada e deformada para Ogden Alongamento de $10 \%$ - excentricidade de 0,5

Figura 4.87 - Configuração indeformada e deformada para Ogden Alongamento de $20 \%$ - excentricidade de 0,5

Figura 4.88 - Configurações deformadas com excentricidade de 0,5 mm para Ogden com $0 \%, 10 \%$ e $20 \%$ de alongamento 164

Figura 4.89 - Variação da pressão crítica - Excentricidade de 0,5mm - 
Ogden

Figura 4.90 - Variação da tensão máxima trativa principal em função do alongamento aplicado, para excentricidade de $0,5 \mathrm{~mm}$ e funcional de energia Ogden 1

Figura 4.91 - Configuração indeformada e deformada para Neo Hooke -

Sem alongamento - excentricidade de 0,5

Figura 4.92 - Configuração indeformada e deformada para Neo Hooke Alongamento de $10 \%$ - excentricidade de 0.5 166

Figura 4.93 - Configuração indeformada e deformada para Neo Hooke Alongamento de $20 \%$ - excentricidade de 0,5

Figura 4.94 - Configurações deformadas com excentricidade de $0,5 \mathrm{~mm}$ para Neo Hooke com $0 \%, 10 \%$ e $20 \%$ de alongamento

Figura 4.95 - Variação da pressão crítica - Excentricidade de 0,5mm Neo Hooke

Figura 4.96 - Variação da tensão máxima trativa principal em função do alongamento aplicado, para excentricidade de $0,5 \mathrm{~mm}$ e funcional de energia Neo Hooke

Figura 4.97 - Configuração indeformada e deformada para Neo Hooke Sem alongamento - excentricidade de 1,0

Figura 4.98 - Configuração indeformada e deformada para Neo Hooke Alongamento de $10 \%$ - excentricidade de 1,0

Figura 4.99 - Configuração indeformada e deformada para Neo Hooke Alongamento de $20 \%$ - excentricidade de 1,0

Figura 4.100 - Configurações deformadas com excentricidade de 1,0 mm para Ogden com $0 \%, 10 \%$ e $20 \%$ de alongamento

Figura 4.101 - Variação da pressão crítica - Excentricidade de 1,0mm -

Ogden

Figura 4.102 - Variação da tensão máxima trativa principal em função do alongamento aplicado, para excentricidade de $1,0 \mathrm{~mm}$ e funcional de energia Ogden 1

Figura 4.103 - Configuração indeformada e deformada para Neo Hooke Sem alongamento - excentricidade de 1,0

Figura 4.104 - Configuração indeformada e deformada para Neo Hooke - 
Alongamento de $10 \%$ - excentricidade de 1,0

Figura 4.105 - Configuração indeformada e deformada para Neo Hooke Alongamento de $20 \%$ - excentricidade de 1,0

Figura 4.106 - Configurações deformadas com excentricidade de 1,0 mm para Neo Hooke com $0 \%, 10 \%$ e $20 \%$ de alongamento 176

Figura 4.107 - Variação da pressão crítica - Excentricidade de 1,0mm Neo Hooke 176

Figura 4.108 - Variação da tensão máxima trativa principal em função do alongamento aplicado, para excentricidade de $1,0 \mathrm{~mm}$ e funcional de energia Neo Hooke

Figura 4.109 - Configuração indeformada e deformada para Neo Hooke Sem alongamento - excentricidade de 1,5

Figura 4.110 - Configuração indeformada e deformada para Neo Hooke Alongamento de $10 \%$ - excentricidade de 1,5

Figura 4.111 - Configuração indeformada e deformada para Neo Hooke Alongamento de $20 \%$ - excentricidade de 1,5

Figura 4.112 - Configurações deformadas com excentricidade de $1,5 \mathrm{~mm}$ para Ogden com $0 \%, 10 \%$ e $20 \%$ de alongamento

Figura 4.113 - Variação da pressão crítica - Excentricidade de 1,5mm -

Ogden

Figura 4.114 - Variação da tensão máxima trativa principal em função do alongamento aplicado, para excentricidade de $1,5 \mathrm{~mm}$ e funcional de energia Ogden 1

Figura 4.115 - Configuração indeformada e deformada para Neo Hooke Sem alongamento - excentricidade de 1,5

Figura 4.116 - Configuração indeformada e deformada para Neo Hooke Alongamento de $10 \%$ - excentricidade de 1,5

Figura 4.117 - Configuração indeformada e deformada para Neo Hooke Alongamento de $20 \%$ - excentricidade de 1,5

Figura 4.118 - Configurações deformadas com excentricidade de 1,5 mm para Neo Hooke com $0 \%, 10 \%$ e $20 \%$ de alongamento

Figura 4.119 - Variação da pressão crítica - Excentricidade de 1,5mm Neo Hooke 
Figura 4.120 - Variação da tensão máxima trativa principal em função do alongamento aplicado, para excentricidade de $1,5 \mathrm{~mm}$ e funcional de energia Neo Hooke

Figura 4.121 - Configuração indeformada e deformada para Ogden Sem alongamento - excentricidade de 2,0

Figura 4.122 - Configuração indeformada e deformada para Ogden Alongamento de $10 \%$ - excentricidade de 2,0

Figura 4.123 - Configuração indeformada e deformada para Ogden Alongamento de $20 \%$ - excentricidade de 2,0

Figura 4.124 - Configurações deformadas com excentricidade de 2,0 mm para Ogden com $0 \%, 10 \%$ e $20 \%$ de alongamento

Figura 4.125 - Variação da pressão crítica - Excentricidade de 2,0mm Ogden

Figura 4.126 - Variação da tensão máxima trativa principal em função do alongamento aplicado, para excentricidade de 2,0 $\mathrm{mm}$ e funcional de energia Ogden 1

Figura 4.127 - Configuração indeformada e deformada para Neo Hooke Sem alongamento - excentricidade de 2,0

Figura 4.128 - Configuração indeformada e deformada para Neo Hooke Alongamento de $10 \%$ - excentricidade de 2,0

Figura 4.129 - Configuração indeformada e deformada para Neo Hooke Alongamento de $20 \%$ - excentricidade de 2,0

Figura 4.130 - Configurações deformadas com excentricidade de 2,0 mm para Neo Hooke com 0 \%, $10 \%$ e $20 \%$ de alongamento

Figura 4.131 - Variação da pressão crítica - Excentricidade de 2,0mm Neo Hooke

Figura 4.132 - Variação da tensão máxima trativa principal em função do alongamento aplicado, para excentricidade de 2,0 $\mathrm{mm}$ e funcional de energia Ogden 1

Figura 4.133 - Variação da pressão crítica em função da excentricidade e do alongamento para Ogden 1

Figura 4.134 - Variação da pressão crítica em função da excentricidade e do alongamento para Neo Hooke 
Figura 4.135 - Variação da tensão máxima trativa principal em função da excentricidade e do alongamento para Ogden 1

Figura 4.136 - Variação da tensão máxima trativa principal em função da excentricidade e do alongamento para Neo Hooke

Figura 4.137 - Configuração indeformada e deformada para Neo Hooke Alongamento de $10 \%$ - excentricidade de $0.5-C_{10}=50 \mathrm{KPa}$

Figura 4.138 - Configuração indeformada e deformada para Neo Hooke Alongamento de $10 \%$ - excentricidade de $0,5-C_{10}=40 \mathrm{KPa}$

Figura 4.139 - Configuração indeformada e deformada para Neo Hooke Alongamento de $10 \%$ - excentricidade de $0,5-C_{10}=30 \mathrm{KPa}$

Figura 4.140 - Configuração indeformada e deformada para Neo Hooke Alongamento de $10 \%$ - excentricidade de $0,5-C_{10}=20 \mathrm{KPa} \quad 200$

Figura 4.141 - Configuração indeformada e deformada para Neo Hooke Alongamento de $10 \%$ - excentricidade de $0,5-C_{10}=10 \mathrm{KPa} 200$ Figura 4.142 - Variação da pressão crítica - Excentricidade de 0,5mm Neo Hooke

Figura 4.143 - Variação da tensão máxima trativa principal em função da diminuição da constante elástica do funcional de energia Neo Hooke para excentricidade de $0,5 \mathrm{~mm}$

Figura 4.144 - Configuração indeformada e deformada para Neo Hooke Alongamento de $10 \%$ - excentricidade de $1,0-C_{10}=50 \mathrm{KPa}$

Figura 4.145 - Configuração indeformada e deformada para Neo Hooke Alongamento de $10 \%$ - excentricidade de $1,0-C_{10}=40 \mathrm{KPa}$ 203

Figura 4.146 - Configuração indeformada e deformada para Neo Hooke Alongamento de $10 \%$ - excentricidade de $1,0-C_{10}=30 \mathrm{KPa}$ 204

Figura 4.147 - Configuração indeformada e deformada para Neo Hooke Alongamento de $10 \%$ - excentricidade de $1.0-C_{10}=20 \mathrm{KPa}$ 205

Figura 4.148 - Configuração indeformada e deformada para Neo Hooke Alongamento de $10 \%$ - excentricidade de $1.0-C_{10}=10 \mathrm{KPa}$ 205 Figura 4.149 - Variação da pressão crítica - Excentricidade de 1,0mm Neo Hooke 206 
Figura 4.150 - Variação da tensão máxima trativa principal em função da diminuição da constante elástica do funcional de energia Neo Hooke para excentricidade de $1,0 \mathrm{~mm}$

Figura 4.151 - Configuração indeformada e deformada para Neo Hooke Alongamento de $10 \%$ - excentricidade de $1,5-C_{10}=50 \mathrm{KPa}$

Figura 4.152 - Configuração indeformada e deformada para Neo Hooke Alongamento de $10 \%$ - excentricidade de $1,5-C_{10}=40 \mathrm{KPa}$ 208

Figura 4.153 - Configuração indeformada e deformada para Neo Hooke Alongamento de $10 \%$ - excentricidade de $1,5-C_{10}=30 \mathrm{KPa}$ 209

Figura 4.154 - Configuração indeformada e deformada para Neo Hooke Alongamento de $10 \%$ - excentricidade de $1,5-C_{10}=20 \mathrm{KPa}$

Figura 4.155 - Configuração indeformada e deformada para Neo Hooke Alongamento de $10 \%$ - excentricidade de $1,5-C_{10}=10 \mathrm{KPa} \quad 210$ Figura 4.156- Variação da pressão crítica - Excentricidade de 1,5mm Neo Hooke

Figura 4.157 - Variação da tensão máxima trativa principal em função da diminuição da constante elástica do funcional de energia Neo Hooke para excentricidade de $1,5 \mathrm{~mm}$

Figura 4.158 - Configuração indeformada e deformada para Neo Hooke Alongamento de $10 \%$ - excentricidade de $2,0-C_{10}=50 \mathrm{KPa}$

Figura 4.159 - Configuração indeformada e deformada para Neo Hooke Alongamento de $10 \%$ - excentricidade de $2,0-C_{10}=40 \mathrm{KPa}$

Figura 4.160 - Configuração indeformada e deformada para Neo Hooke Alongamento de $10 \%$ - excentricidade de $2,0-C_{10}=30 \mathrm{KPa}$

Figura 4.161 - Configuração indeformada e deformada para Neo Hooke Alongamento de $10 \%$ - excentricidade de $2,0-C_{10}=20 \mathrm{KPa}$

Figura 4.162 - Configuração indeformada e deformada para Neo Hooke Alongamento de $10 \%$ - excentricidade de $2,0-C_{10}=10 \mathrm{KPa}$

Figura 4.163 - Variação da pressão crítica - Excentricidade de 2,0mm Neo Hooke

Figura 4.164 - Variação da tensão máxima trativa principal em função da 
diminuição da constante elástica do funcional de energia Neo Hooke para excentricidade de $2,0 \mathrm{~mm}$

Figura 4.165 - Variação da pressão crítica em função da excentricidade e da diminuição da constante elástica

Figura 4.166 - Variação da tensão máxima trativa principal em função da excentricidade e da diminuição da constante elástica

Figura 5.1 - Gráfico tensão deformação apresentado por Sacks para o tecido arterial

Figura 5.2 - Aproximação dos funcionais de energia estáveis

Figura 5.3 - Gráfico demonstrativo de análise de convergência do elemento de casca para o funcional de energia Ogden 1

Figura 5.4 - Configuração indeformada e deformada para o elemento representativo da aorta sem alongamento

Figura 5.5 - Configuração indeformada e deformada para o elemento representativo da aorta com alongamento de $10 \%$

Figura 5.6 - Configuração indeformada e deformada para o elemento representativo da aorta com alongamento de $20 \%$

Figura 5.7 - Variação da pressão em função do alongamento (\% do comprimento inicial)

Figura 5.8 - Configuração indeformada e deformada para o elemento representativo da aorta sem alongamento

Figura 5.9 - Configuração indeformada e deformada para o elemento representativo da aorta com alongamento de $10 \%$

Figura 5.10 - Configuração indeformada e deformada para o elemento representativo da aorta com alongamento de $20 \%$

Figura 5.11 - Variação da pressão em função do alongamento (\% do comprimento inicial)

Figura 5.12 - Configuração indeformada e deformada para o funcional de energia de Delfino com geometria sem imperfeição

Figura 5.13 - Configuração indeformada e deformada para o funcional de energia de Delfino com geometria com imperfeição inicial 232

Figura 5.14 - Configuração indeformada e deformada para o funcional de 
energia de Sacks com geometria sem imperfeição

Figura 5.15 - Configuração indeformada e deformada para o funcional de energia de Sacks com espessura apenas da camada media

Figura 5.16 - Configuração indeformada e deformada para o funcional de energia de Sacks com espessura apenas da camada media e geometria de D. P. Sokolis (2007)

Figura 5.17 - Configuração indeformada e deformada proposta por A.

Dorfmann (2010) para os aneurismas

Figura 5.18 - Posição da imperfeição local

Figura 5.19 - Variação da pressão crítica em função da diminuição da constante elástica no local da imperfeição

Figura 5.20 - Variação da tensão máxima trativa principal em função da diminuição da constante elástica no local da imperfeição

Figura 5.21 - Configurações deformadas de cada uma dos casos estudados para a variação da constante elástica $(\mathrm{KPa})$

Figura 5.22 - Variação da pressão crítica em função da diminuição da constante elástica no local da imperfeição

Figura 5.23 - Variação da tensão máxima trativa principal em função da diminuição da constante elástica no local da imperfeição 242 Figura 5.24 - Configurações deformadas de cada uma dos casos estudados para a variação da constante elástica $(\mathrm{KPa})$

Figura 6.1 - Gráfico comparativo da pressão crítica numérica e experimental

Figura 6.2 - Gráfico comparativo da tensão máxima com a pressão crítica

Figura 6.3 - Posição da imperfeição anelar inferior (a) e superior (b) 248 Figura 6.4 - Variação da pressão crítica $(\mathrm{mmHg})$ em função da diminuição da espessura na região anelar inferior

Figura 6.5 - Variação da pressão crítica ( $\mathrm{mmHg}$ ) em função da diminuição da espessura na região anelar superior

Figura 6.6 - Posição das imperfeições para os casos estudados (a) caso

1, (b) caso 2, (c) caso 3, (d) caso 4; figuras fora de escala 
Figura 6.7 - Variação da pressão crítica em função de imperfeições locais

Figura 6.8 - Variação da pressão crítica em função da excentricidade para Ogden1

Figura 6.9 - Variação da pressão crítica em função da excentricidade para Neo Hooke 254

Figura 6.10 - Variação da pressão crítica em função da redução da constante elástica

Figura 6.11 - Configurações deformadas (a) sem imperfeição (b) experimental, (c), (d), (e) e (f) com excentricidades de 0,5 mm, 1,0 mm, $1,5 \mathrm{~mm}$ e 2,0 $\mathrm{mm}$ respectivamente, sem alongamento

Figura 6.12 - Configurações deformadas (a) sem imperfeição (b) experimental, (c), (d), (e) e (f) com excentricidades de 0,5 mm, 1,0 mm, $1,5 \mathrm{~mm}$ e $2,0 \mathrm{~mm}$ respectivamente, com alongamento de $10 \%$

Figura 6.13 - Configurações deformadas (a) sem imperfeição (b) experimental, (c), (d), (e) e (f) com excentricidades de 0,5 mm, 1,0 mm, $1,5 \mathrm{~mm}$ e $2,0 \mathrm{~mm}$ respectivamente, com alongamento de $20 \%$ 259 Figura 6.14 - Variação da pressão crítica através dos dados propostos por Sacks

Figura 6.15 - Configuração indeformada e deformada proposta por A. Dorfmann para os aneurismas

Figura 6.16 - Par de parâmetros a e b da Equação de Delfino para diversas pressões internas 


\section{Lista de tabelas}

Tabela 2.1 - Propriedades mecânicas da artéria 51

Tabela 3.1 - Pressões críticas do ensaio $1 \quad 70$

Tabela 3.2 - Pressões críticas do ensaio 2

Tabela 3.3 - Pressões críticas do ensaio $3 \quad 75$

Tabela 3.4 - Pressões críticas do ensaio 4

Tabela 3.5 - Pressões críticas do ensaio $5 \quad 80$

Tabela 3.6 - Pressões críticas do ensaio 6

Tabela 3.7 - Pressões de referências 85

Tabela 3.8 - Volumes de referência 86

Tabela 4.1 - Valores da constante elástica de Ogden 1

Tabela 4.2 - Valores da constante elástica de Neo Hooke 95

Tabela 4.3 - Valores da constante elástica de Arruda-Boyce 96

Tabela 4.4 - Pressão crítica em função da diminuição da espessura da região anelar inferior 123

Tabela 4.5 - Variação da tensão máxima trativa principal em função da diminuição da espessura da região anelar 125

Tabela 4.6 - Pressão crítica em função da diminuição da espessura da região anelar superior

Tabela 4.7 - Variação da tensão máxima trativa principal em função da diminuição da espessura da região anelar

Tabela 4.8-Variação da tensão máxima trativa principal para o caso 1137 Tabela 4.9-Variação da tensão máxima trativa principal para o caso 2144 Tabela 4.10-Variação da tensão máxima trativa principal para o caso 3151 Tabela 4.11-Variação da tensão máxima trativa principal para o caso 4158 Tabela 4.12-Variação da tensão máxima trativa principal em função do alongamento aplicado, para excentricidade de $0,5 \mathrm{~mm}$ e funcional de energia Ogden 1

Tabela 4.13 - Variação da tensão máxima trativa principal em função do 
alongamento aplicado, para excentricidade de $0,5 \mathrm{~mm}$ e funcional de energia Neo Hooke

Tabela 4.14 - Variação da tensão máxima trativa principal em função do alongamento aplicado, para excentricidade de $1,0 \mathrm{~mm}$ e funcional de energia Ogden 1

Tabela 4.15 - Variação da tensão máxima trativa principal em função do alongamento aplicado, para excentricidade de $1,0 \mathrm{~mm}$ e funcional de energia Neo Hooke

Tabela 4.16 - Variação da tensão máxima trativa principal em função do alongamento aplicado, para excentricidade de $1,5 \mathrm{~mm}$ e funcional de energia Ogden 1

Tabela 4.17 - Variação da tensão máxima trativa principal em função do alongamento aplicado, para excentricidade de $1,5 \mathrm{~mm}$ e funcional de energia Neo Hooke

Tabela 4.18 - Variação da tensão máxima trativa principal em função do alongamento aplicado, para excentricidade de $2,0 \mathrm{~mm}$ e funcional de energia Ogden 1

Tabela 4.19 - Variação da tensão máxima trativa principal em função do alongamento aplicado, para excentricidade de 2,0 $\mathrm{mm}$ e funcional de energia Neo Hooke

Tabela 4.20 - Variação da pressão crítica em função da excentricidade e do alongamento

Tabela 4.21 - Variação da tensão máxima trativa principal em função da excentricidade e do alongamento

Tabela 4.22 - Variação da tensão máxima trativa principal em função da diminuição da constante elástica do funcional de energia Neo Hooke para excentricidade de $0,5 \mathrm{~mm}$

Tabela 4.23 - Variação da tensão máxima trativa principal em função da diminuição da constante elástica do funcional de energia Neo Hooke para excentricidade de $1,0 \mathrm{~mm}$

Tabela 4.24 - Variação da tensão máxima trativa principal em função da diminuição da constante elástica do funcional de energia Neo Hooke para excentricidade de $1,5 \mathrm{~mm}$ 
Tabela 4.25 - Variação da tensão máxima trativa principal em função da diminuição da constante elástica do funcional de energia Neo Hooke para excentricidade de $2,0 \mathrm{~mm}$

Tabela 4.26 - Variação da pressão crítica em função da excentricidade e da diminuição da constante elástica

Tabela 4.27 - Variação da tensão máxima trativa principal em função da excentricidade e da diminuição da constante elástica 218

Tabela 5.1 - Valores da constante elástica de Ogden $1 \quad 223$

Tabela 5.2 - Valores da constante elástica de Yelow 223

Tabela 5.3 - Variação da pressão crítica e da tensão máxima trativa principal em função da diminuição da constante elástica no local da imperfeição

Tabela 5.4 - Variação da pressão crítica e da tensão máxima trativa principal em função da diminuição da constante elástica e da espessura no local da imperfeição

Tabela 6.1 - Comparação da pressão crítica $(\mathrm{mmHg})$ numérica e experimental

Tabela 6.2 - Diferença percentual dos ensaios numéricos e experimentais

Tabela 6.3 - Comparação das tensões principais máximas (KPa) que ocorrem no instante da pressão crítica 